\title{
Correspondence
}

\section{Nutrition and elimination diets}

Sir,

We were most interested to read the paper by David and colleagues, ${ }^{1}$ and would wholeheartedly endorse their statement that 'avoidance of multiple foods is potentially hazardous and requires continued paediatric and dietetic supervision'. Moreover we feel that the social and psychological implication of these diets should not be overlooked. No doubt this paper will be widely quoted by those wishing to discourage the use of these diets especially as it is entitled 'Nutritional hazards of elimination diets . . .'.

The authors' data suggest, however, that on balance the children they looked after were as well nourished as the control children. From their table, 10 of 23 children on the elimination diet were receiving less than $75 \%$ of the recommended daily allowance for calcium, but they were as well nourished as the controls in terms of other nutrients, and $90 \%$ of the controls were receiving less than half the recommended daily allowance for vitamin D. As they rightly point out, the recommended daily allowance may not be a good guide to true requirements, and there is evidence that children grow normally on calcium intakes well below this. ${ }^{2}$ Furthermore, poor growth and the development of rickets are probably more dependent on vitamin $\mathrm{D}$ status than on calcium intake. ${ }^{2}$ It is doubtless prudent to ensure such children receive the recommended daily allowance of calcium, but supplementation to achieve this is easily instituted. We are at a loss to explain the authors' self deprecation when they have illustrated the very point they seem to disclaim, namely that properly supervised and supplemented exclusion diets are not nutritionally hazardous. Perhaps their paper ought to have been entitled 'the safety of properly supervised elimination diets in children with atopic eczema'!

\section{A J Cant and J A Bailes St George's Hospital, London SW17 ORE}

Dr David and co-workers comment:

The study referred to ${ }^{1}$ simply examined the intake of a few selected nutrients. Neither the patients nor the controls were described as being well nourished, and no data on height, weight, growth velocity, skin fold thickness, or biochemical parameters were given. The title might have been less cautious had the study been of normal children. There is concern, however, that some children with atopic eczema not on diets are either thin or short, or both, a subject of current study in several centres. Further, some children with eczema are kept out of sunlight for prolonged periods, and an abnormal vitamin $\mathrm{D}$ status may render them especially vulnerable to adverse effects of a low calcium intake, possibly explaining the occurrence of rickets in one patient. ${ }^{3}$ This case showed that even in a children's hospital with two experienced full time dietitians there can be great difficulty in ensuring 'proper' supervision of exclusion diets. To describe elimination diets as safe, with the difficulties of maintaining regular supervision, the problems of interpretation of recommended dietary amounts, the worries about poor growth, and the hazards of anaphylactic shock ${ }^{4}$ seems slightly premature and possibly misleading.

\section{References}

1 David TJ, Waddington E, Stanton RHJ. Nutritional hazards of elimination diets in children with atopic eczema. Arch Dis Child 1984;59:323-5.

2 Walker ARP. The human requirement of calcium: should low intakes be supplemented? Am J Clin Nutr 1972;25:518-30.

3 David TJ, Lakhani PK, Haeney MR. Severe atopic eczema, recurrent pneumococcal meningitis, and recurrent eczema herpeticum. $J R$ Soc Med 1984;77:696-7.

4 David TJ. Anaphylactic shock during elimination diets for severe atopic eczema. Arch Dis Child 1984;59:983-6.

\section{Role of the microcomputer in formulating neonatal nutrition regimens}

Sir,

Dr MacMahon presents a computerised solution to the problem of intravenous nutrition in neonates. ${ }^{1}$ We venture to suggest that this is 'BASICALLY' an abuse of his pharmacy and possibly his computer.

In our experience it is not necessary to make frequent adjustments to parenteral nutrition regimens, nor where it is, is it safe or desirable to delegate to the junior staff. In 14 months we have provided parenteral nutrition for 21 neonates for more than seven days (19 babies were less than $1.5 \mathrm{~kg}$ at birth, and of these 12 were less than $1.0 \mathrm{~kg}$ ), in total providing 526 patient days of intravenous feeding solution. The bulk of this has been provided using three standard formulas, which vary only in their amino acid content $(10,20$, or $30 \mathrm{ml} / \mathrm{kg}$ of Vamin) accounting in total for $87 \%$ of the prepared bags. Of the remaining 71 bags it has been necessary to compute only 10 changes to the basic formulas. For example, we have found it necessary to provide an increased sodium solution, but once having derived the pharmacy work sheet this has been applicable to several patients.

In practice our system has worked so well, with considerable savings in pharmacy time and money, that we are now actively investigating the long term stability of our standard solutions to permit bulk preparation.

We agree that the solution to intravenous nutrition is 'BASIC' but feel frankly that the high level language 